\title{
Synthethic peptide used to develop antibodies for detection of polyhedrin from monodon baculovirus (MBV)
}

\author{
Attaphon Satidkanitkul ${ }^{1,2}$, Paisarn Sithigorngul ${ }^{3}$, Wiwat Sang-oum ${ }^{2}$, \\ Sombat Rukpratanporn ${ }^{4}$, Siriporn Sriurairatana ${ }^{2}$, Boonsirm Withayachumnankul ${ }^{2}$, \\ Timothy Flegel ${ }^{1,2, *}$ \\ ${ }^{1}$ Department of Biotechnology and ${ }^{2}$ Centex Shrimp, Faculty of Science, Mahidol University, Rama 6 Road \\ Bangkok 10400, Thailand \\ ${ }^{3}$ Department of Biology, Faculty of Science, Srinakarinwirot University, Sukhumvit Soi 23, Bangkok 10100, Thailand \\ ${ }^{4}$ Marine Biotechnology Research Unit and National Center for Genetic Engineering and Biotechnology (BIOTEC), \\ Chulalongkorn University, Phyathai Road, Bangkok 10400, Thailand
}

\begin{abstract}
The use of previously published primers to amplify the monodon baculovirus (MBV) polyhedrin gene sequence by polymerase chain reaction (PCR) from post larvae (PL) of Thai Penaeus monodon resulted in failure. As a result, the putative polyhedrin protein of MBV was isolated from infected PL by homogenization, differential centrifugation and density gradient centrifugation with verification by transmission electron microscopy (TEM). By SDS-PAGE, a single major protein band at $58 \mathrm{kDa}$ was obtained from the putative polyhedrin fraction and this corresponded to a previous report of the molecular weight of polyhedrin from MBV. When used for N-terminal sequence analysis, the putative polyhedrin protein yielded a sequence of 25 amino acids (M F D D S M M M N M D D L S G D Q K M V L T L A) that did not correspond to the deduced amino acid sequence derived from a previous report of a putative MBV polyhedrin gene amplicon. Despite this, a synthetic peptide of our 25 amino acid sequence (25Pmbv) was conjugated with bovine serum albumin and used as an antigen for antiserum production in mice. Using immunohistochemistry with tissue sections of PL infected with MBV or other viruses, the mouse anti-25Pmbv antiserum showed strong immunoreactivity to occlusion bodies of MBV only. It also showed strong reactivity to the $58 \mathrm{kDa}$ putative polyhedrin protein in Western blots. Altogether, the results suggest that the $58 \mathrm{kDa}$ protein is Thai MBV polyhedrin and that a previously reported MBV polyhedrin gene sequence may represent another protein or polyhedrin from a different variety of MBV.
\end{abstract}

KEY WORDS: Immunohistochemistry $\cdot$ Monodon baculovirus $\cdot$ MBV $\cdot$ Penaeus monodon $\cdot$ Polyclonal antibody $\cdot$ Polyhedrin

\section{INTRODUCTION}

Monodon baculovirus (MBV) is a major virus that infects the hepatopancreas of cultivated shrimp species (Lightner 1996) and may cause growth retardation at late stages of cultivation (Flegel et al. 2004). MBV occurs commonly in Thailand (Fegan et al. 1991), elsewhere in Asia (Lightner 1996), in Australia (Owens 1997) and in India (Manivannan et al. 2004). It infects all life stages from larvae to adults, and infections in shrimp hatcheries are believed to be initiated by larval contamination from faeces of infected broodstock 
(Lightner 1996). MBV-infected hepatopancreatic tubule epithelial cells exhibit single to multiple, polygonal occlusion bodies within enlarged nuclei with marginated chromatin. These occlusion bodies are typical for nuclear polyhedrosis viruses (NPV) and consist of a major $58 \mathrm{kDa}$ protein called polyhedrin (Bonami et al. 1997) that acts as a kind of matrix to protect embedded virions when the occlusion bodies are sloughed into the midgut and subsequently shed in the faeces. Because polyhedrin is produced in large quantities, it is a good potential target for development of MBV immunodiagnostic reagents.

In Thailand, the most commonly used method for MBV diagnosis in post larvae (PL) is microscopic examination of squash mounts stained with 1 to $2 \%$ malachite green in a solution of $2.8 \% \mathrm{NaCl}$ (Fegan et al. 1991). Juvenile shrimp from growout ponds are usually monitored using hepatopancreatic smears stained with hematoxylin and eosin (H\&E) (Alday de Graindorge \& Flegel 1999) or by normal polymerase chain reaction (PCR) of faeces or haemolymph using primers previously published for a PCR-ELISA assay (Belcher \& Young 1998). However, in order to eliminate heavily infected batches before rearing ponds are stocked, PL are the most frequently assayed for MBV. Microscopic examination of squash mounts is the method of choice because it is inexpensive. However, the process is tedious, especially for large numbers of samples and it requires some experience on the part of technicians to distinguish between MBV viral inclusions and other materials that often appear in squash mounts. PCR assays and other molecular methods are regarded as too expensive for routine use. Development of a rapid and inexpensive immunological diagnostic method would be an alternative approach.

Thus, we adopted an initial strategy to prepare MBV polyhedrin protein by PCR amplification of the MBV polyhedrin gene as previously reported (Chang et al. 1993, Lu et al. 1993, Hsu et al. 2000). After experiencing multiple failures in using published primers to amplify appropriate amplicons from Thai MBVinfected Penaeus monodon, as did Belcher (1998) with Australian MBV, we changed our strategy and focused on direct isolation of MBV polyhedrin protein for use as an immunogen.

\section{MATERIALS AND METHODS}

Preparation and purification of polyhedrin. Approximately 4000 to 5000 Penaeus monodon PL at stages 10 to 15 were obtained from a shrimp hatchery in Chachoengsao province Thailand. From this batch, $20 \mathrm{PL}$ were randomly selected and checked for MBV infection by microscopic examination of malachite green-stained squash mounts, while another sample of 20 PL was used for nested PCR assay following a previously described protocol (Belcher \& Young 1998) that yielded MBV-specific amplicons of 533 and $361 \mathrm{bp}$. After confirmation of MBV infection, PL were stunned in ice water and then placed in a beaker with 4 to $5 \times$ their volume of distilled water. The plunger was removed from a $50 \mathrm{ml}$ plastic syringe with no needle and a thoroughly mixed portion of the PL and water was poured into the syringe with the syringe opening held closed. Then the plunger was added and the mixture was forced through the syringe opening into a receiving beaker on ice. This disruption procedure was repeated until all of the PL-water mixture had been ejected into the receiving beaker. This cycle was repeated 10 times in rapid succession or until microscopic inspection of the homogenate showed that none or few of the larvae remnants still contained an intact hepatopancreas. The homogenate was then filtered through a $100 \mu \mathrm{m}$ Nitex screen. The residue was resuspended in $4 \times$ volume of distilled water and shaken before repeating the filtration. The residue was discarded and the filtrate was centrifuged at $4000 \times g$ for $20 \mathrm{~min}$ at $4^{\circ} \mathrm{C}$. The supernatant was then ultracentrifuged at $100000 \times g$ for $3 \mathrm{~h}$ at $4^{\circ} \mathrm{C}$ and the pellet was re-suspended in $\mathrm{TN}$ buffer $(0.01 \mathrm{M}$ Tris- $\mathrm{HCl}, 0.1 \mathrm{M}$ $\mathrm{NaCl}, \mathrm{pH}$ 7.4) for layering onto the top of a Urografin ${ }^{\mathrm{TM}}$ gradient (20 to $60 \%$ ) and centrifugation at $120000 \times g$ for $16 \mathrm{~h}$ at $4^{\circ} \mathrm{C}$. After ultracentrifugation, sample bands were removed and repelleted by centrifugation at $120000 \times g$ for $1 \mathrm{~h}$ at $4^{\circ} \mathrm{C}$. The pellets were resuspended in a minimum amount of TN buffer and examined for the presence of polyhedrin protein and viral particles by transmission electron microscopy (TEM) using negative staining.

TEM. A droplet of each sample band was placed on the specimen grid coated with Formvar carbon (Electron Microscopy Science). After allowing about $10 \mathrm{~min}$ for suspension settlement, excess liquid was removed by touching a filter paper to the edge of the grid. After the grid had dried, a droplet of staining solution $(2 \%$ phosphotungstic acid in distilled water, $\mathrm{pH}$ 7.4) was placed on the grid for about $1 \mathrm{~min}$ before removal of excess liquid by touching a filter paper to the edge of the grid followed by further drying (Haschemeyer \& Meyer 1970). The grids were examined for the presence of polyhedrin protein and viral particles by TEM (Hitachi H-7100).

PCR for hepatopancreatic parvovirus (HPV). Since HPV may occur in the shrimp hepatopancreas and since HPV particles are similar in size and morphology to MBV polyhedrin, the putative polyhedrin fraction was confirmed to be free of HPV particles by using PCR to detect HPV. The fraction was subjected to DNA extraction following the protocol in the QIAamp ${ }^{\circledR}$ DNA 
mini kit handbook (Qiagen). PCR to detect HPV was carried out using an Ezee Gene ${ }^{\circledR}$ HPV441 single-step PCR mini kit (Shrimp Biotechnology Business Unit, National Center of Genetic Engineering and Biotechnology, Bangkok, Thailand) according to the kit instructions. PCR reaction products were electrophoresed in a $1 \%$ agarose gel at $50 \mathrm{~V}$ for $1 \mathrm{~h}$ followed by staining with $1 \mathrm{\mu g} \mathrm{ml}^{-1}$ ethidium bromide solution for 3 to $5 \mathrm{~min}$ and de-staining for $30 \mathrm{~min}$ with water before observation under UV light. The absence of an expected $441 \mathrm{bp}$ HPV amplicon was considered to indicate freedom from HPV.

SDS-PAGE analysis, protein sequencing and peptide synthesis. TEM fractions containing putative polyhedrin from Urografin ${ }^{\mathrm{TM}}$ gradient were separated by $10 \%$ SDS-PAGE in accordance with the method described by Laemmli (1970). They were electrophoresed for $1.5 \mathrm{~h}$ at $100 \mathrm{~V}$ and part of the gel was stained using Coomassie brilliant blue R-250. For Nterminal sequencing by Edman degradation, protein bands from an SDS-PAGE gel were transferred to a PVDF membrane and a portion carrying the putative polyhedrin protein band was sent to the Biomolecular Research Facility, University of Newcastle, Australia. A synthetic oligopeptide (25Pmbv) based on the Nterminal sequence was synthesized by GenScript Corporation, USA.

Antigen preparation. The synthetic oligopeptide 25Pmbv was conjugated to bovine serum albumin (BSA) at an approximate molar ratio of 5:1. Briefly, $4 \mathrm{mg}$ of synthetic peptide and $10 \mathrm{mg}$ of BSA were added to $1 \mathrm{ml}$ of phosphate buffered saline (PBS; $0.15 \mathrm{M}$ phosphate buffer in $0.85 \% \mathrm{NaCl}_{1} \mathrm{pH} 7.4$ ) containing $20 \mu \mathrm{l}$ of $25 \%$ glutaraldehyde followed by gentle mixing for 1 to $2 \mathrm{~h}$. Glutaraldehyde was eliminated by dialysis against 3 changes of PBS for $48 \mathrm{~h}$. The peptide conjugate (25Pmbv-BSA) was divided into small aliquots and stored at $-20^{\circ} \mathrm{C}$. Glycine-BSA (Gly-BSA) conjugate was prepared using a similar protocol and used for antiserum absorption and as a negative control.

Immunization. Four Swiss albino mice (6 wk old) were immunized intraperitoneally with $0.4 \mathrm{mg}$ of BSA conjugated synthetic peptide mixed with complete Freund's adjuvant for a total volume of $150 \mu \mathrm{l}$ per mouse (antigen:adjuvant 1:1 v/v). The mice were boosted 3 times at 2 wk intervals with the same preparation mixed with incomplete Freund's adjuvant as previously described (Sithigorngul et al. 2002). One week after the 4th injection, antisera were collected, absorbed with Gly-BSA and tested for immunoreactivity by immunohistochemistry, dot blot assay and Western blot assay.

Immuno dot blots. The putative polyhedrin band derived from Urografin ${ }^{\mathrm{TM}}$ gradient $\left(5 \mathrm{mg} \mathrm{ml}^{-1}\right)$,
25Pmbv-BSA $\left(0.4 \mathrm{mg} \mathrm{ml}^{-1}\right)$, and Gly-BSA $(0.4 \mathrm{mg}$ $\mathrm{ml}^{-1}$ ) were spotted onto a nitrocellulose membrane $\left(1 \mathrm{ml} \mathrm{spot}{ }^{-1}\right)$ then incubated with mouse anti-25Pmbv antiserum at a dilution of 1:200 in 5\% Blotto (5\% nonfat dry milk, $0.1 \%$ Triton-X-100 in PBS) for $4 \mathrm{~h}$. After extensive washing in $0.5 \%$ Blotto, the membrane was incubated in horseradish peroxidase conjugated goat anti-mouse IgG heavy and light chain specific antibody (GAM-HRP; BioRad) at 1:1000 dilution for $3 \mathrm{~h}$. The membrane was then washed extensively as before and incubated in a substrate mixture containing $0.006 \%$ hydrogen peroxide, $0.03 \%$ diaminobenzidine (DAB) and $0.05 \%$ cobalt chloride in PBS. The specificity of the mouse antiserum producing antibodies that displayed immunoreactivity was confirmed for specificity by Western blot and immunohistochemistry.

Western blots. For Western blot analysis, samples resolved by SDS-PAGE were electroblotted onto nitrocellulose membranes using a Transblot apparatus (BioRad). The membranes were incubated in $5 \%$ Blotto for 10 min, treated with 1:200 mouse anti-25Pmbv antiserum for $4 \mathrm{~h}$ and then processed as described above in 'Immuno dot blots' section.

Immunohistochemistry. Cephalothoraxes from normal PL and MBV- or HPV-infected PL were fixed in Davidson's fixative and processed for paraffin sectioning as previously described (Lightner 1996). Serial sections $(7 \mu \mathrm{m}$ thickness) were prepared and processed for indirect immunoperoxidase staining using various dilutions of antisera previously absorbed with formalin fixed hepatopancreatic homogenate from uninfected Penaeus monodon. This was followed by treatment with GAM-HRP diluted 1:1000 with $10 \%$ calf serum in PBS ( $\mathrm{pH} 7.4$ ) and visualization by incubation with $0.03 \%$ DAB and $0.06 \%$ hydrogen peroxide in PBS. Preparations were counterstained with hematoxylin and eosin Y (H\&E) (Lightner 1996), dehydrated in a graded ethanol series, cleared in xylene and mounted in permount (Sithigorngul et al. 1999). A positive immunoreaction was visualized as brown coloration at the site of MBV infection against the purple blue of basophilic hepatopancreatic tubule epithelial cells and nuclei. Tissues from $P$. monodon infected with HPV were used to determine immunochemical crossreactivity since HPV also infects the hepatopancreas of P. monodon

\section{RESULTS AND DISCUSSION}

Two thin, sharp bands were found at 30 and $50 \%$ Urografin $^{\mathrm{TM}}$ after gradient ultracentrifugation of homogenates from PL infected with MBV. When examined by TEM, the band at $30 \%$ Urografin $^{\mathrm{TM}}$ contained mostly tissue debris and neither polyhedrin protein 
particles nor viral particles were observed. However, at $50 \%$ Urografin $^{\mathrm{TM}}$ (Fig. 1), particles of 20 to $23 \mathrm{~nm}$ diameter that resembled empty and full particles like the MBV polyhedrin sub-units previously described (Bonami et al. 1997) were seen. These resembled MBV polyhedrin subunits previously described (Bonami et al. 1997). Some exhibited a hexagonal outline (Fig. 2). When the preparation was analyzed by SDS-PAGE, one major protein band was observed (Fig. 3) at approximately $58 \mathrm{kDa}$ (named M58). This was similar to MBV polyhedrin previously described (Bonami et al. 1997).

$\mathrm{N}$-terminal sequence analysis of the $58 \mathrm{kDa}$ protein gave 25 amino acid residues (M F D D S M M M E N M D D L S G D Q K M V L T L A) that were partially homologous to the sequence of a protein from Spodoptera litura nucleopolyhedrovirus (NCBI accession no. gi/15617607/), Spodoptera exigua nucleopolyhedrovirus (NCBI accession no. gi/9634331/) and poly protein from sweet potato feathery mottle virus (NCBI accession no. gi/29466293/). However, the deduced protein sequence did not match deduced protein sequences derived from PCR amplification products reportedly derived from the polyhedrin gene of MBV from Taiwanese Penaeus monodon (Chang et al. 1993, Lu et al. 1993, Hsu et al. 2000) or previously reported polyhedrin protein sequences of NPV listed at GenBank. In contrast, the insect NPV sequences at GenBank displayed very high homology.



Fig. 1. Urografin ${ }^{\mathrm{TM}}$ ultracentrifugation tube for purification of monodon baculovirus (MBV) polyhedrin. The hepatopancreatic homogenate from post larvae of Penaeus monodon was separated in a Urografin step gradient. The band at $50 \%$

Urografin (arrow) contained putative polyhedrin protein
The 25 amino acid residue sequence from the $\mathrm{N}$ terminus of M58 was used to synthesize an oligopeptide $(25 \mathrm{Pmbv})$ of approximately $80 \%$ purity as verified

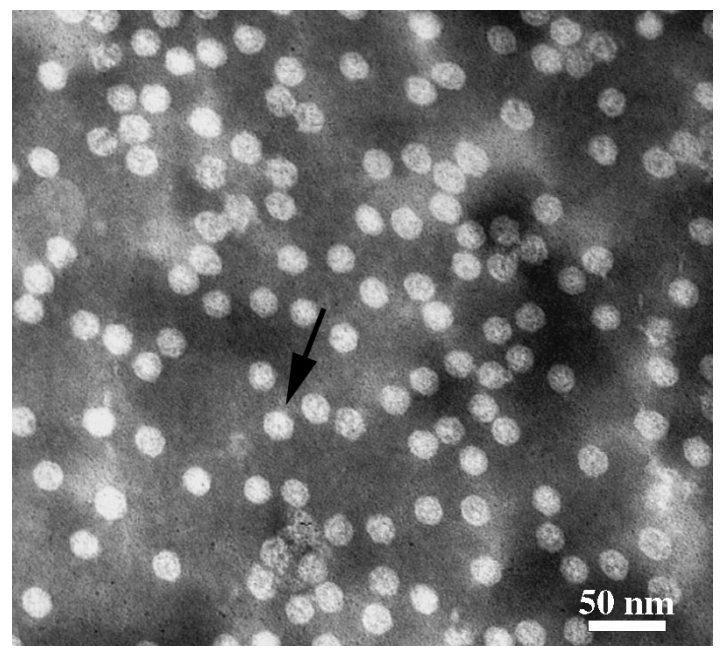

Fig. 2. Transmission electron micrograph of negatively stained, putative polyhedrin protein particles from the $50 \%$ Urografin fraction. They resemble full and empty forms. Arrow points to hexangonal particle

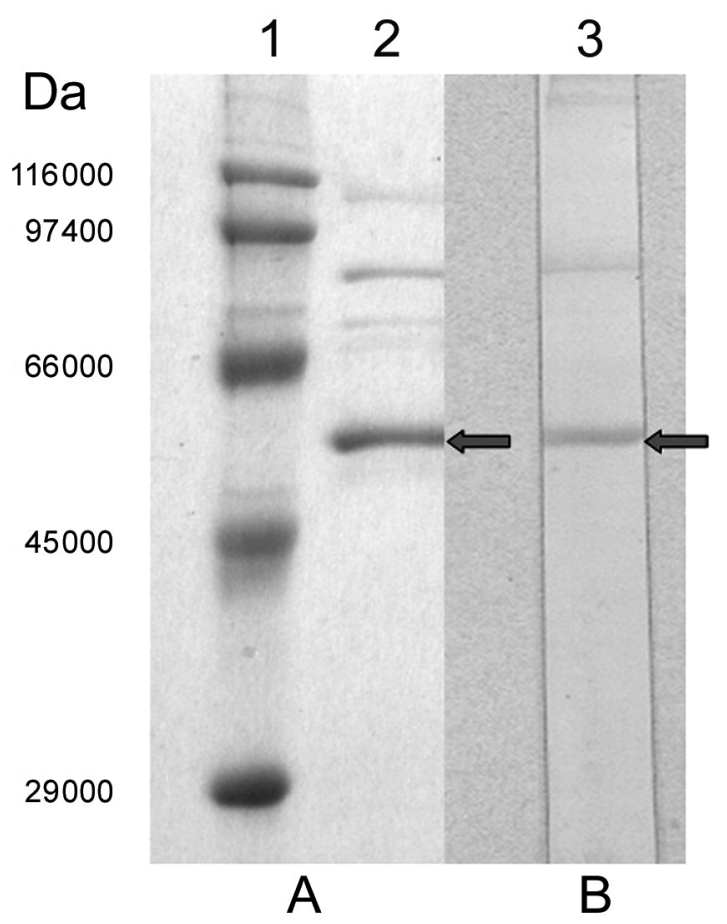

Fig. 3. (A) SDS-PAGE and (B) Western blot analysis of the $50 \%$ Urografin band. Lanes 1 and 2 show an SDS-PAGE gel stained with Coomassie blue with the molecular marker in Lane 1 and the Urografin band in Lane 2, where a major protein band can be seen at approximately $58 \mathrm{kDa}$ (arrow). A Western blot using mouse anti-25Pmbv antiserum shows a strong binding reaction at the same position in Lane 3 (arrow) and a weaker reaction at around $80 \mathrm{kDa}$. Molecular weights (Da) are shown on the left 
by RP-HPLC and MALDI-TOF mass spectrometry performed by GenScript Corporation, USA. Mouse antiserum to BSA-conjugated 25Pmbv (25Pmbv-BSA) at 1:50 showed strong specific immunoreactivity to MBV intra-nuclear occlusions in the hepatopancreas of Penaeus monodon by means of immunohistochemistry (Fig. 4). In some preparations, light immunoreactivity was also observed around the basement membrane of



Fig. 4. Immunohistochemistry of hepatopancreatic tissue from MBV-infected Penaeus monodon. The mouse 4 anti-25Pmbv antiserum gave a strong immunoreactivity (brown color) only to occlusion bodies in hepatopancreatic cells (arrows)

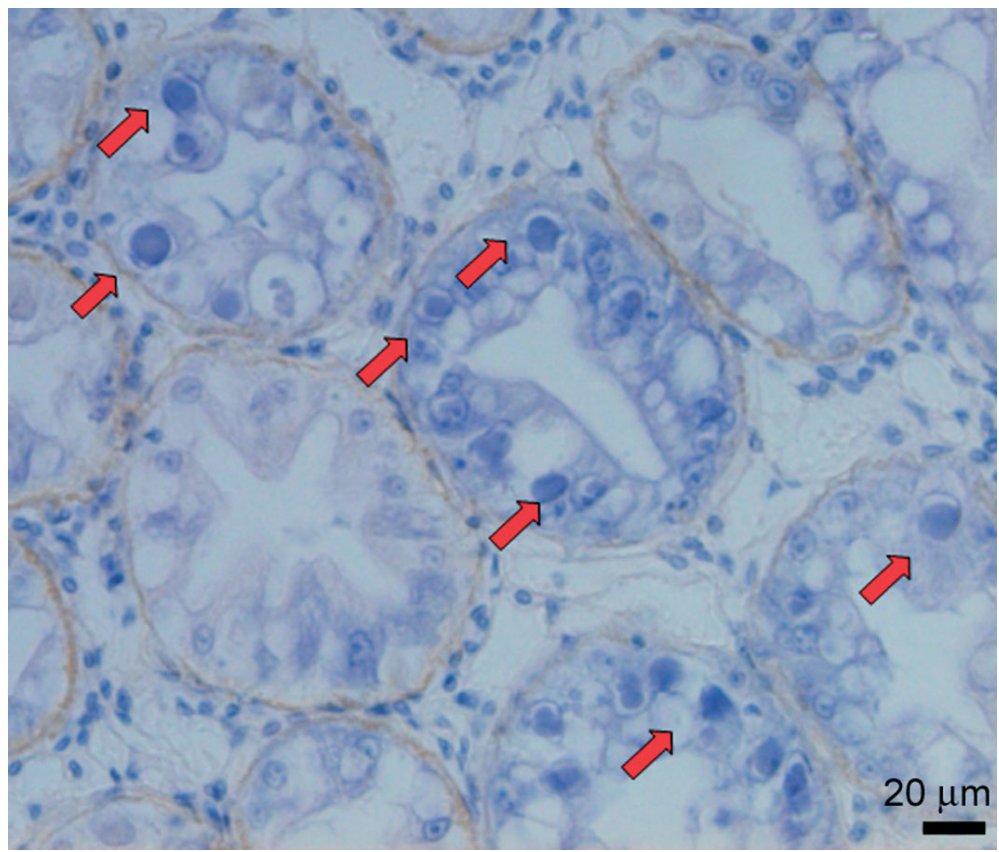

Fig. 5. Immunohistochemistry of the hepatopancreas from hepatopancreatic parvocirus (HPV)-infected Penaeus monodon. The mouse 4 anti-25Pmbv antiserum did not show cross-reactivity to HPV inclusion bodies (arrows) or normal tubule epitheial cell nuclei but did give a light reaction with the basement membrane of the tubule epithelium the hepatopancreatic tubules (Fig. 4) and may have resulted from cross-reactivity due to incomplete absorption of the antiserum with shrimp tissue homogenate. Apart from this, there was no cross reactivity with other tissues or with uninfected PL tissue sections or with HPV-infected tissue sections (Fig. 5). Dot blot analysis of the antiserum against 25Pmbv-BSA, Gly-BSA and putative polyhedrin fraction derived from $50 \%$ Urografin $^{\mathrm{TM}}$ (M58) fraction, revealed strong specific binding to 25Pmbv-BSA and M58 protein but only very light immunoreactivity to Gly-BSA (Fig. 6).

Our results from TEM, SDS-PAGE and immunohistochemistry strongly suggest that M58 represents MBV polyhedrin as described by Bonami et al. (1997). However, the N-terminal sequence of M58 does not correspond to the deduced protein sequence reported for Taiwanese MBV polyhedrin (Lu et al. 1993). The disparity in results may be explained by the fact that the Taiwanese gene sequence (225 deduced amino acid residues) represented less than half of the $58 \mathrm{kDa}$ polyhedrin protein and may not have included the $\mathrm{N}$ terminus. In contrast, it is interesting that several attempts to use the p35 and p36 primers (Chang et al. 1993, Lu et al. 1993) to amplify Thai and Australian MBV polyhedrin gene fragments resulted in failure. However, the use of PCR primers published for diagnosis of Australian MBV (Belcher \& Young 1998) were successful with MBV from Thailand, Australia and India (Manivannan et al. 2002, 2004). Therefore, another possibility is that Thai and Australian MBV may differ sufficiently from Taiwanese MBV that the Taiwanese PCR primers will not work. Further work on full polyhedrin gene sequences from regional MBV isolates would be needed to resolve this issue.

Isolation and purification of polyhedrin from MBV-infected PL is a tedious and lengthy process when dependent on dissection and accumulation of the hepatopancreas from hundreds of specimens. Our method based on mass isolation by hydro force is simpler and more rapid but would also be inconvenient and problematic for continual production of standardized diagnostic reagents. In the absence of continuous shrimp cell lines, it would be more convenient to use viral proteins expressed 


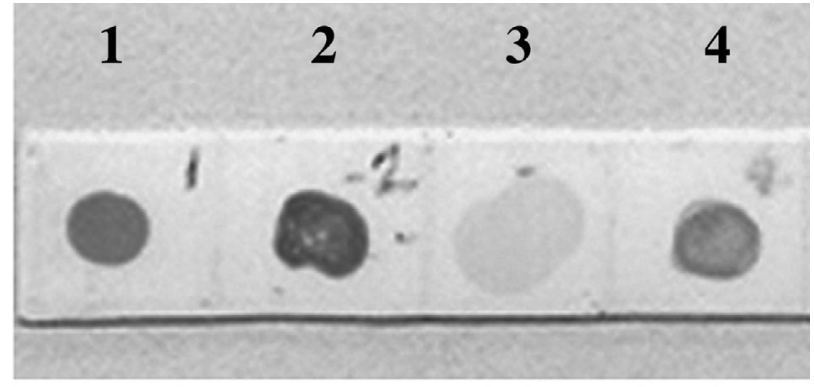

Fig. 6. Dot-blot test showing immunoreactivity of mouse 4 antiserum at 1:200 dilution with varies type of antigens. Dot 1: denatured form of $50 \%$ Urografin conentrate suspension. Dot 2: BSA-25Pmbv conjugated protein. Dot 3: BSA-Glycine. Dot 4: native form of $50 \%$ Urografin concentrate suspension

in bacteria, yeast or insect cell expression systems. Knowing the N-terminal animo acid sequence of Thai MBV should facilitate isolation of the polyhedrin gene and production of standardized immuno-based reagents. In the meantime, our conjugated synthetic peptide is being used as an antigen for selection of monoclonal antibodies specific for MBV polyhedrin.

Acknowledgements. This work was supported by a research grant and student fellowship to A.S., both from the Thai National Center for Genetic Engineering and Biotechnology (BIOTEC) and by funds from Mahidol University.

\section{LITERATURE CITED}

Alday de Graindorge V, Flegel TW (1999) Diagnosis of shrimp diseases with emphasis on the black tiger prawn Penaeus monodon. Multimedia Asia, Bangkok

Belcher CR (1998) Molecular detection and characterisation of monodon baculovirus. Thesis, University of Queensland, Brisbane

Belcher CR, Young PR (1998) Colourimetric PCR-based detection of monodon baculovirus in whole Penaeus monodon postlarvae. J Virol Methods 74:21-29

Bonami JR, Aubert H, Mari J, Poulos BT, Lightner DV (1997) The polyhedra of the occluded baculoviruses of marine decapod crustacea: a unique structure, crystal organization, and proposed model. J Struct Biol 120:134-145

Chang PS, Lo CF, Kou GH, Lu CC, Chen SN (1993) Purification and amplification of DNA from Penaeus monodontype baculovirus (MBV). J Invertebr Pathol 62:116-120

Fegan DF, Flegel TW, Sriurairatana S, Waiakrutra M (1991) The occurrence, development and histopathology of monodon baculovirus in Penaeus monodon in Southern Thailand. Aquaculture 96:205-217

Flegel TW, Nielsen L, Thamavit V, Kongtim S, Pasharawipas $\mathrm{T}$ (2004) Presence of multiple viruses in non-diseased, cultivated shrimp at harvest. Aquaculture 240:55-68

Haschemeyer RH, Meyer RJ (1970) Negative staining. In: Hayat MA (ed) Principles and techniques in electron microscopy, Vol 2. Oxford University Press, Oxford, p 99-147

Hsu YL, Wang KH, Yang YH, Tung MC, Hu CH, Lo CF, Wang $\mathrm{CH}$, Hsu T (2000) Diagnosis of Penaeus monodon-type baculovirus by PCR and by ELISA of occlusion bodies. Dis Aquat Org 40:93-99

Laemmli UK (1970) Cleavage of structural proteins during the assembly of the head of bacteriophage T4. Nature 227: $680-685$

Lightner DV (1996) A handbook of pathology and diagnostic procedures for diseases of penaeid shrim. World Aquaculture Society, Baton Rouge, LA

Lu CC, Tang FJK, Kou GH, Chen SN (1993) Development of a Penaeus monodon-type baculovirus (MBV) DNA probe by polymerase chain reaction and sequence analysis. J Fish Dis 16:551-559

Manivannan S, Otta SK, Karunasagar I, Karunasagar I (2002) Multiple viral infection in Penaeus monodon shrimp postlarvae in an Indian hatchery. Dis Aquat Org 48:233-236

Manivannan S, Kennedy B, Karunasagar I, Karunasagar I (2004) Prevalence of monodon baculovirus in wild Metapenaeus species along the southwest coast of India. Aquaculture 232:63-67

Owens L (1997) Special topic review: the history of the emergence of viruses in Australian prawn aquaculture. World J Microbiol Biotechnol 13:427-431

Sithigorngul P, Panchan N, Vilaivan T, Sithigorngul W, Petsom A (1999) Immunochemical analysis and immunohistochemical localization of crustacean hyperglycemic hormone from eyestalk of Macrobrachium rosenbergii. Comp Biochem Physiol A 124B:73-80

Sithigorngul P, Rukpratanporn S, Longyant S, Chaivisuthangkura P, Sithigorngul W, Menasveta P (2002) Monoclonal antibodies specific to yellow-head virus (YHV) of Penaeus monodon. Dis Aquat Org 49:71-76

Submitted: October 25, 2004; Accepted: December 30, 2004 Proofs received from author(s): June 2, 2005 